\title{
Pesquisa social, prática profissional e interdisciplinaridade*
}

\section{Social research, professional practice and interdisciplinarity}

\section{Myrian Veras BAPTISTA*}

\begin{abstract}
Resumo: O presente artigo é transcrição de palestra proferida pela professora doutora Myrian Veras Baptista em evento denominado "Pesquisa social, prática profissional e interdisciplinaridade" coordenado pela professora doutora Jussara Ayres Bourguignon. O texto apresenta reflexões importantes sobre o processo de pesquisa social e os desafios que se põem aos profissionais no cotidiano de sua prática profissional em um contexto social, econômico e político diversificado e complexo.
\end{abstract}

Palavras-chave: Pesquisa social. Prática profissional. Interdisciplinaridade.

\begin{abstract}
This article is a full transcription of the lecture presented at the Universidade Estadual de Ponta Grossa by professor Myrian Veras Baptista, Ph.D. during an event called "Social research, professional practice and Interdisciplinarity", which was organized by professor Jussara Ayres Bourguignon, Ph.D. The lecture brings about important reflections concerning the social research process and the challenges faced by social workers in their everyday practice, which takes place in intricate social, economic and political contexts.
\end{abstract}

Keywords: Social research. Professional practice. Interdisciplinarity.

Recebido em: 17/03/2010. Aceito em: 20/04/2010.

\footnotetext{
* Palestra proferida pela professora doutora Myrian Veras Baptista na Universidade Estadual de Ponta Grossa em 25/09/2009. Exposição transcrita pelas acadêmicas Caroline da Silva e Mayana Franccine Rotella sob a supervisão da professora doutora Édina Schimanski do curso de Serviço Social da Universidade Estadual de Ponta Grossa e revisado pela autora.

** Doutora em Serviço Social pela Pontifícia Universidade Católica de São Paulo, professora titular da Pontifícia Universidade Católica de São Paulo.
} 
É um prazer estar em Ponta Grossa, uma terra em que eu já morei há muito tempo. Era outra Ponta Grossa a que eu conheci nos anos de 1960 ... Ver a Ponta Grossa de hoje - tão dinâmica! E esta universidade! Da qual posso falar especificamente da área do Serviço Social: reconhecida em todo o Brasil como um centro de formação e de construção de conhecimento importante para a área. Por tudo isso, fico muito satisfeita e agradecida por ter a oportunidade de estar aqui com vocês e refletir sobre algumas questões.

Eu quero também cumprimentar os alunos - tanto da graduação, quanto da pós-graduação. Tenho um carinho especial pelo relacionamento professor/aluno - alguns momentos preciosos que vivi nesta minha vida foram dando aulas... em Curitiba... no Rio de Janeiro... e, há muito tempo, estou dando aulas em São Paulo. E esses encontros instigantes com os alunos têm sido sempre prazerosos.

Vou balizar esta minha reflexão a partir de duas temáticas que norteiam este encontro: o seu tema-título - Prática Profissional, Pesquisa Social e Interdisciplinaridade - e, o lançamento do livro da Jussara Ayres Bourguignon, que trata da particularidade histórica da pesquisa no Serviço Social.

Sobre o livro da Jussara Ayres Bourguignon, quero lembrar que uma maneira de apreender a qualidade de um livro é percebendo o quanto de reflexões ele desperta em seus leitores. O livro da Jussara descortinou, para mim, tantos caminhos que sempre será pouco o tempo que tenho para falar sobre ele.

Jussara vai buscar na teoria social de Karl Marx e no método dialético que a fundamenta, as bases para sua investigação. E esse não é um caminho fácil, embora (no entender de Lucien Goldmann, ${ }^{1}$ entendimento do qual partilho) seja o único que permite, tendo como ponto de partida fatos isolados e abstratos, compreendêlos e explicá-los, extraindo deles sua significação socio-histórica.

Esse livro, que se interroga sobre a particularidade histórica da pesquisa no Serviço Social

Em Dialética e Cultura. Rio de Janeiro, Paz e Terra, 1979 e sobre os desafios daí decorrentes, parte da perspectiva de que é da natureza da profissão a construção de conhecimentos pela via da investigação, não colocando, portanto, a prática da pesquisa apenas como uma possibilidade, mas como uma condição para dar qualidade ao modo de refletir e intervir dos assistentes sociais comprometidos com as demandas e com as possibilidades de enfrentamento que lhes são postas historicamente.

Nesse processo, as mediações entre a elaboração teórica, a pesquisa, a prática e os desafios que se põem aos profissionais se dão de maneira complexa em um contexto social, econômico e político extremamente diversificado: em face de questões muito específicas, o profissional que investiga não tem apenas que analisar o quê, o como e o por quê dos acontecimentos, tem ainda que estabelecer uma crítica, tomar uma posição e decidir por um determinado tipo de intervenção.

O norte fornecido pela teoria social de Marx para o conhecimento da sociedade, de suas relações e dos fatos sociais por elas construídos, se dá a partir da perspectiva de totalidades concretas. Quando se tem uma compreensão mais clara dessa categoria analítica é que podemos perceber os vínculos das diferentes dimensões postas no tema central deste encontro: a prática profissional, a pesquisa social e a interdisciplinaridade.

A perspectiva de totalidades concretas, como categoria analítica, significa que a realidade estudada deve ser apreendida como um todo articulado de totalidades parciais, as quais somente poderão ser compreendidas quando integradas ao conjunto estrutural de que fazem parte: o que está velado na imediaticidade da apreensão de uma totalidade parcial vai se desvelando na medida em que se insere aquela parcialidade em totalidades mais amplas das quais é parte.

Nesse sentido, a reflexão sobre as abordagens temáticas deste encontro - prática profissional, pesquisa social e interdisciplinaridade - não é feita sob a perspectiva de totalidades epistemológicas, nas quais cada uma delas compõe uma unidade. O que se busca é apreendê-las como totalidades parciais de um mesmo processo - 0 
processo de formação, que tem por objetivo a compreensão, a explicação e a construção de propostas de intervenção sobre questões relacionadas a diferentes dimensões da sociedade, em conjunturas socio-históricas específicas. Ainda que essas abordagens ocorram em níveis diferenciados de ação, estão nela imbricadas, constituindo uma unidade de diversos - e não uma identidade - e supondo a construção de capacidades de análises totalizantes que possibilitem a compreensão do processo e a apreensão de seu movimento. Isso significa que, na compreensão e na explicação dos fatos sociais e - por conseqüência - na intervenção sobre eles, é legítima a abordagem setorial quando informada pela concepção de totalidade, que recusa a indiferenciação das abordagens e assume a compreensão de que estas constituem unidade teórico-disciplinares que precisam se articular organicamente com as demais.

Quando Marx $x^{2}$ reflete sobre o seu próprio processo de investigação, é o encadeamento dos fatos e de suas relações empíricas que são objeto imediato de reflexão. Seu ponto de partida é a apreensão do fato social tal como ele se mostra empiricamente e, nesse processo, vai deixando claro que a aparência imediata do objeto não permite apreendê-lo em sua concretude - essa empiria, ao mesmo tempo em que o revela, oculta sua essência - por isso, essa aparência imediata é chamada de abstração. Diz: se a aparência do fenômeno expressasse sua essência, não se precisaria investigar. Então, cabe à razão desvelar a essência do objeto. É preciso um esforço para, a partir da negação dialética dessa empiria como fato essencial, reconstruir o objeto como concreto pensado. Marx explica o sentido desse concreto: o concreto é concreto porque é a síntese de muitas determinações, a unidade do diverso.

Nesse sentido, quando o profissional de Serviço Social assume essa perspectiva teórica, tem clareza de que a realidade não se colo-

\footnotetext{
2 Essa reflexão de Marx é encontrada em seus apontamentos econômicos dos anos 1857/1858, publicados em 1939 sob o titulo de Grundrisse. Fonte: Karl Marx, Manuscritos econômicofilosóficos e outros textos escolhidos - seleção de textos de José Arthur Giannotti e tradução de José Carlos Bruni. São Paulo, Abril Cultural 1978, (Os pensadores).
}

ca imediatamente à sua compreensão; que os fatos com os quais trabalha, na imediaticidade de sua ação, são expressão de uma realidade muito mais complexa que precisa ser desvelada. Uma pequena história que vivi pode ajudar a percepção dessa complexidade. Eu, em 1979, participei do III Congresso Brasileiro de Assistentes Sociais (aquele que, posteriormente, foi conhecido como Congresso da Virada), como membro da Comissão Técnica. Esse Congresso mobilizou um grande número de profissionais e, mesmo em uma cidade como São Paulo, ele apareceu como um evento importante. Então, como representante da Comissão Técnica, fui convidada pela Rede Globo, juntamente com uma colega - Yolanda Heloisa de Souza - para dar uma entrevista sobre o mesmo. Yolanda era uma pessoa com muita facilidade para falar e foi muito brilhante nessa entrevista. Quando a entrevista acabou, o câmera, intrigado, perguntou a ela: Nessa perspectiva que a senhora dá ao Serviço Social, como a senhora explicaria o "trombadinha"? ${ }^{3}$ Essa pergunta foi motivada por um fato ocorrido na véspera - um assalto que chamara atenção da mídia: um menino tinha entrado em uma casa no Morumbi. Então, a Yolanda deu uma resposta que traduz uma primeira aproximação à complexidade de que eu estou falando: "Para mim, o "trombadinha" é um sobrevivente da mortalidade infantil, que continua lutando pela sua sobrevivência, correndo o risco do assalto".

Essa resposta traz um exemplo do caminho da razão para apreender o objeto, compreendê-lo, buscar suas determinações e desvelar as vias de equacionamento dos desafios que ele expressa. Nesse processo, a ação retira de questões práticas, questões teóricas: põe demandas teóricas à reflexão como norte para seu modo de intervenção.

Nessa perspectiva, o processo para apreender o objeto se dá por aproximações sucessivas - o que vai permitir que a cada uma dessas aproximações à realidade vá assumindo um novo sentido, mais claro e mais completo. Marx, quando descreve a processualidade de uma investi-

\footnotetext{
3 Naquela época, o termo para designar o adolescente infrator era esse.
} 
gação diz: Parece que o correto é começar pelo real e pelo concreto, que são a pressuposição prévia e efetiva [...] No entanto, graças a uma observação mais atenta, temos conhecimento que isso é falso. A população é uma abstração se desprezarmos, por exemplo, as classes que a compõem, Por seu lado, estas classes são uma palavra vazia se ignorarmos os elementos em que repousam: o trabalho assalariado, o capital, etc. [...] Assim, se começássemos pela população, teríamos uma representação caótica do todo, e através de uma determinação mais precisa, através de uma análise, chegaríamos a conceitos cada vez mais simples. Chegados a esse ponto, teríamos que voltar a fazer a viajem de modo inverso, até dar de novo com a população, mas desta vez não com uma representação caótica de um todo, porém com uma rica totalidade de determinações e relações diversas. ${ }^{4}$

Nesse processo, a progressão do conhecimento é feita em patamares, descortinando novos horizontes, substituindo progressivamente o que de início era uma realidade caótica em uma imagem mais precisa e mais complexa. Essa progressão nunca vai abarcar a realidade por inteiro, mas a cada aproximação nós a entendermos melhor: não apenas compreendemos a sua estrutura, mas também identificamos as determinações que a conformaram.

Eu tenho outra história que venho utilizado para dar a ideia desse processo. Em uma viagem que fiz com Maria Lucia Martinelli, para um encontro da Alaess - Associação Latino-Americana de Escolas de Serviço Social - em Lima, no Peru, resolvemos conhecer Machu Picchu. Pegamos um avião e fomos para Cuzco onde pegamos um trem para Machu Picchu. O trem começou lentamente seu caminho. Andou um pouquinho e parou. Voltou de ré. Andou para frente outro pouco, novamente parou, depois, voltou... E assim ficou, em idas e vindas... Nós já estávamos desanimadas. Então, percebemos que a cada ida e a cada vinda o nosso horizonte se modificava, a paisagem ficava mais ampla - porque Machu Picchu fica em local muito mais alto que Cuzco e, como a montanha é extensa, o trem vai em

\footnotetext{
${ }^{4}$ No texto "O método da economia política", já referido.
}

zigue-zague. Eu pensei, então, que tínhamos aí um bom exemplo das aproximações sucessivas: você inicialmente vê apenas a estação, as pessoas... depois, começa ver as casas, os quintais, as praças e, a cada aproximação, quanto mais se ganha altura, mais se percebe a cidade, sua organização, as distâncias, o horizonte...

Essa relação com o método das sucessivas aproximações pode ser completada com a "metáfora topológica" feita por Michael Löwy quando construiu a "alegoria do mirante" 5 para analisar os diferentes modos de apreensão da realidade. Nessa alegoria, Löwy compara o cientista social a um pintor de paisagem e observa que irá depender do lugar onde o artista situa seu observatório (o ponto de vista de classe ${ }^{6}$ ) a dimensão do horizonte que se põe à sua observação. Os mirantes mais baixos mostram partes mais limitadas da paisagem, que se distinguem não apenas pela diferença na altura, mas também pela diferença de posições do pintor: uma mesma paisagem pode ser vista por ângulos distintos e complementares. Diz: existe uma parte da paisagem que é vista de todas as alturas: é a "zona de consenso" entre os diversos pontos de vista, geralmente limitada ao nível mais imediato do conhecimento.

Na continuidade, Löwy reflete sobre a utilidade dessa metáfora para figurar que o mirante não oferece senão uma possibilidade objetiva de uma visão determinada de paisagem - a paisagem não depende apenas do observatório, mas principalmente da forma de olhar e da arte do pintor; que as apreensões da "paisagem" sempre se fazem a partir de um determinado ponto de vista; que os limites do horizonte não dependem apenas do observador, mas da posição em que ele se encontra; que o observador do nível superior tanto pode dar conta dos limites como das visões verdadeiras dos níveis inferiores; existem, ainda, as determinações relativamente autônomas em relação às classes sociais, à nacionalidade, à geração, ao sexo, à religião, à vinculação a certas

\footnotetext{
${ }^{5}$ Michael Löwy conclui seu livro As Aventuras de Karl Marx contra o Barão de Munchhausen. Marxismo e positivismo na sociologia do conhecimento (São Paulo, Cortez, 1994, $5^{\text {a }}$ ed.) com um capítulo que denomina "As paisagens da verdade e a alegoria do mirante (Para uma sociologia critica do conhecimento)".

${ }^{6} \mathrm{Na}$ hipótese de Löwy, o observatório mais alto expressa o ponto de vista do proletariado.
} 
categorias sociais ou organizações...

Na perspectiva da teoria social de que estamos tratando, o observador que está no alto da montanha, precisa perceber o todo, mas também suas particularidades. Tem que ser provido de "binóculos" - instrumentais teórico-metodológicos - que lhe permitam compreender e explicar as diferentes instâncias construtoras dessa totalidade, suas determinações e as mediações que as conformam. Há um conteúdo político nessa apreensão que predispõe para determinados modos de percepção do real. Não basta estar no alto da montanha se não se quiser (ou não se conseguir) ver aquilo que se evidencia.

Dentre os instrumentais teórico-metodológicos, no contexto da teoria social marxista, que vão possibilitar o desvelamento da complexidade das situações que se põem no campo da pesquisa e da intervenção profissional, estão suas categorias analíticas.

A primeira e mais central categoria analítica - a totalidade - fui referida desde o início desta reflexão: é a categoria ontológica fundamental do pensamento marxiano. Em Marx, a realidade social constitui uma totalidade concreta - um complexo de totalidades - com suas possibilidades, seus limites e seus problemas. Essa complexidade evidencia-se nas relações sociais heterogêneas e contraditórias - unidade de diversos. Reconhecer essas totalidades parciais, com seus diferentes graus de complexidade, significa, antes de mais nada, apreender as mediações que se articulam na sua construção, compreender suas relações, seus nexos, no sentido de ultrapassar a empiria e apreender sua estrutura significativa, sua dinâmica e sua articulação com a dinâmica da sociedade.

Essas articulações não se dão de forma indiferenciada, nem igualitárias: algumas totalidades parciais têm maior peso e influência sobre as demais. Charles Bettelheim ${ }^{7}$ quando, em meados do século passado, analisou a transição para a economia socialista que ocorria em diferentes países, apontou esse complexo de totalidades, destacando que aquela transição

\footnotetext{
${ }^{7}$ Charles Bettelheim. A transição para a economia socialista.
} Trad. Sergio Goes de Paula. Rio, Zahar, 1969. assumia a configuração de estruturas complexas de relações com dominante: uma combinação específica resultante de diversos modos de relação, sendo que um deles era dominante - impregnava e modificava as condições de funcionamento e de desenvolvimento de todas as demais. Marx já havia assinalado esse tipo de dominação: Em todas as formas da sociedade se encontra uma produção determinada, superior a todas as demais e cuja situação aponta sua posição e influência sobre as outras. É uma luz universal em que se embebem todas as cores e que as modifica em sua particularidade. É um éter especial que determina o peso específico de todas as coisas emprestando relevo a seu modo de ser. ${ }^{8}$

Para esse tipo de relação dominante, usase também o termo hegemonia. Quando falamos, por exemplo, de um pensamento hegemônico, não estamos dizendo que todos ou que a maior parte das pessoas comungue de uma mesma ideia, mas que mesmo havendo diversidade de pensamentos há um pensamento que influencia, modifica e é referência para o modo de ser dos demais.

A apreensão, compreensão e explicação dessas totalidades complexas e de suas relações é naturalmente articulada com a análise das determinações que decorrem do movimento histórico da sociedade: o que significa articular a reflexão teórica com o universo empírico que está sendo pesquisado e com sua conjuntura histórica.

As relações de sociedade, além de heterogêneas, complexas, são também contraditórias: os fatos sociais são contraditórios, as pessoas são contraditórias - não existe uma instância na vida social onde não haja elementos contraditórios.

Francisco Whitaker Ferreira escreveu um livro de planejamento que, no título, expressava essa contradição: Planejamento: sim e não. Não se referia a uma escolha de alternativas - sim ou não - mas ao fato de que o ato de planejar era bom de acordo com algumas circunstâncias, mas não era bom se as circunstâncias fossem outras. Era "sim, se..." e "não, se..." Querendo significar que, como qualquer fato social, o pla-

\footnotetext{
${ }^{8}$ Esta análise é encontrada em "O método da economia política", já referido nesta reflexão.
} 
nejamento está sujeito a situações contraditórias que podem justificar ou não a sua realização. As pessoas são contraditórias e as situações são contraditórias e a apreensão desse contraditório é muito importante para nortear a pesquisa e a prática profissional.

No ano passado, eu orientei uma dissertação de mestrado sobre medidas socioeducativas que evidenciava o quanto uma pessoa pode ser contraditória. Tratava de um adolescente homicida que tinha uma historia infracional muito grande. Ele estava envolvido com o tráfico de drogas e, quando pretendeu sair, vieram matá-lo, e ele matou. Foi um fato que poderia até ser considerado legítima defesa, mas, nas circunstancias em que ocorreu, isso não aconteceu. De qualquer forma, esse adolescente era um traficante e era um homicida. Mas era também um jovem de extrema sensibilidade, um poeta. O pesquisador fez sua história de vida e trouxe à luz suas poesias que falavam do amor por sua mãe, da natureza, do seu desejo de paz...

No processo de conhecimento da realidade, é de fundamental importância a apreensão das relações entre as categorias da universalidade, da particularidade e da singularidade. Lukács, ${ }^{9}$ ao estudar a categoria da particularidade, faz as seguintes observações: Se não distinguirmos ou, pelo menos, delimitarmos reciprocamente e adquirirmos um certo conhecimento de suas mútuas superações entre as categorias universalidade, particularidade e singularidade será impossível nos orientarmos na realidade, na práxis, mesmo no sentido cotidiano da palavra. [...] A dialética do universal, do particular e do singular propicia uma aproximação à compreensão da realidade à medida que se configura como o caráter processual dessa compreensão. O ser em processo não permite a compreensão do real numa dimensão estática, onde se diviniza e fetichiza o universal, como início exclusivo da sua análise concreta. Essa dialética possibilita concretizações críticas pelo processo de descoberta das relações entre os nexos que a compõem. Desconsiderar essa dialética é extinguir

\footnotetext{
9 Georg Lukács em Introdução a uma estética marxista.Sobre a categoria da Particularidade.. Trad. Carlos Nelson Coutinho e Leandro Konder. Rio de Janeiro, Civilização Brasileira, 1978.
}

a concepção histórica do objeto em estudo, bem como a sua permanente dimensão constituinte.

Para Lukács, a aproximação dialética do conhecimento da singularidade não pode ocorrer separadamente de suas múltiplas relações com a particularidade e com a universalidade. Elas já estão contidas no dado imediatamente sensível de cada singularidade, e a realidade e a essência desses dados só podem ser compreendidas quando essas mediações (da particularidade e da universalidade), ocultas na imediaticidade, são evidenciadas. Nesse processo, a dialética universal/particular/singular apreende as condições estruturais e as transformações históricas da realidade, o que possibilita a formulação de leis que expressam a universalidade do processo, possibilitando um retorno - através de muitas mediações - aos fatos singulares da vida. Quanto mais profundamente os nexus da realidade, suas leis e contradições forem concebidos sob a forma de universalidade, mais concreta poderá ser a compreensão de sua singularidade. Por outro lado, de acordo com Lukács, a singularidade de uma situação pode alcançar clareza teórica ao mostrar como as leis universais se particularizam, de forma que uma determinada situação que, por princípio, é irrepetível, pode ser compreendida em sua relação com as leis mais universais do desenvolvimento histórico.

O trato dessa complexidade na apreensão das relações de sociedade vai exigir do profissional da prática, do pesquisador, uma atitude de negação dialética, que vai lhe possibilitar dar sentido crítico à sua investigação e, por consequência, à sua ação: negar os dados imediatos da situação estudada como insuficientes para apanhar sua essência - para sua compreensão e explicação -, desencadeando um processo de questionamento reiterado sobre eles e a partir deles. Essa perspectiva crítica no processo de construção do conhecimento sobre uma determinada situação vai além dela própria, exige também um olhar critico, uma negação dialética, das compreensões e explicações já existentes sobre a questão.

Outro elemento importante a ser refletido, na perspectiva de totalidade, é o sujeito, tanto o sujeito pesquisador, quanto o sujeito pesquisado. Eles são, ao mesmo tempo, sujeitos individuais,

400 Emancipação, Ponta Grossa, 10(1): 395-401, 2010. Disponível em <http://www.revistas2.uepg.br/index.php/emancipacao> 
coletivos e políticos. São individuais - o João, o Antônio, a Maria, com suas histórias, suas subjetividades. São expressão de um coletivo, na medida em que, no dizer de Lucien Gldmann ${ }^{10}$ quase nenhuma ação humana tem por sujeito um indivíduo isolado. O sujeito da ação é um "nós" [...] na sociedade atual cada indivíduo está engajado numa multiplicidade de ações comuns [...] nas quais o grupo de sujeitos não é idêntico e que, tomando essas ações uma importância maior ou menor para o indivíduo, terão influência proporcional a essa importância para o conjunto de sua consciência e de seus comportamentos [...] Desses grupos, o mais importante é a classe social. São sujeitos políticos aqueles que Agnes Heller ${ }^{11}$ chama de "indivíduos": O indivíduo é um particular que "sintetiza" em si mesmo a singularidade casual de sua individualidade e a generalidade universal da espécie. É todo o ser para o qual a própria vida passou a converter-se conscientemente em objeto - tem uma relação consciente com sua própria especificidade e de acordo com circunstâncias e possibilidades abertas pela divisão social do trabalho, pelos marcos de seu modo de vida e pelas escalas de valores vigentes - é capaz de "organizar" sua vida. Heller completa dizendo que esse modo de se relacionar com a vida e com o mundo configura o que irá chamar de "condução da vida" - expressão que toma emprestado de Goethe onde as mesmas categorias e estruturas básicas da vida cotidiana recebem um novo significado, podendo ser negadas ou superadas.

Todas essas reflexões que venho fazendo apontam para o fato de que conhecer e atuar tendo por objeto as relações de sociedade é um trabalho extremamente complexo e que nós não podemos tratar de questões complexas com soluções lineares: há necessidade de um olhar e de uma ação mais expandida. Então, uma categoria norteadora, tanto para o conhecimento, quanto para a prática profissional, é a incompletude toda profissão, assim como toda instituição, são incompletas para a apreensão e a intervenção sobre essa realidade.
Para compreender, explicar e intervir sobre realidades complexas - como as relações sociais - é preciso fazer dos nossos e dos outros olhares uma "unidade na diversidade". Nesse sentido, penso que, muito além da interdisciplinaridade, temos que ter uma perspectiva de transdisciplinaridade: a apreensão da totalidade dinâmica de uma situação é produto da reflexão possibilitada pelas diversidades dos olhares, sem restrições ou barreiras disciplinares, na apropriação dos conhecimentos e na construção das ações. É a busca do "concreto pensado", apenas possível em uma articulação em rede, seja para o conhecimento, seja para a intervenção.

Nessa nossa sociedade complexa, é vedada a cada um de nós individualmente a capacidade de apreensão de diferentes aspectos da realidade, mas é dada a nós a capacidade de fazer parcerias e de construir, em conjunto, sem separação de territórios de saber (que eu acho um prejuízo com relação à perspectiva da totalidade), um conhecimento mais preciso e mais complexo - um "concreto pensado".

Muito obrigada!!!

\footnotetext{
${ }^{10} \mathrm{Na}$ obra já citada.

${ }^{11}$ Em La revolución de la vida cotidiana. Barcelona, 1982, $2^{\mathrm{a}}$ ed.
} 